\title{
CRACK PROPAGATION IN ASR DAMAGED CONCRETE DETECTED BY IMAGE ANALYSIS
}

\author{
TOMOHIRO MIKI* AND HIROKI TSUKAHARA ${ }^{\dagger}$ \\ Kobe University \\ 1-1 Rokkodai, Nada, Kobe, JAPAN \\ e-mail: mikitomo@port.kobe-u.ac.jp \\ ${ }^{\dagger}$ Kobe University \\ 1-1 Rokkodai, Nada, Kobe, JAPAN
}

Key words: Alkali Silica Reaction, Tension Softening Curve, Fracture Energy, Strain Distribution

\begin{abstract}
The present study includes an experimental investigation on the crack propagation in the concrete cracked due to alkali-silica reaction (ASR). The fracture energy and tension softening curves of the ASR damaged concrete were obtained by three-point bending tests for single notched concrete beams. An image analysis by using a digital image correlation method was carried out in order to detect the crack propagation behavior. This method of the image analysis is conducted based on a region-based matching technique in order to calculate the displacement of any portion of the concrete surface. As for the macroscopic damage in the concrete the ASR induced cracks that can be observed on the surface of concrete were evaluated and classified into their widths, lengths and directions. The experiments show that these ASR-induced cracks influence on the crack propagation in the specimen under the bending.
\end{abstract}

\section{INTRODUCTION}

Alkali-silica reaction (ASR) in the concrete is a phenomenon that alkali ingredients such as reactive silica in the aggregate react with the sodium hydroxide in the cement. This reaction sometimes results in gel that causes the volume expansion of concrete and then the crack may occur in the concrete. The ASR damaged concrete in which cracks occur in the macro and micro levels has different mechanical properties to the sound condition. Especially the reduction of the elastic modulus of concrete is remarkable according to the expansion due to the ASR. There is room for argument for the influence of the ASR-induced crack on the mechanical properties of the concrete especially on the fracture properties of the ASR damaged concrete.
The phenomenon of the ASR induced damage in the concrete indicates a significant irregularity that is that the orientation and width of the ASR-induced cracks indicates have no rule and are distributed through the concrete. Since the ASR-induced cracks may influence crack initiation and propagation to occur under the external loads, fundamental experimental data on the mechanical properties of the ASR damaged concrete are necessary in order to establish the constitutive models such as a reference [1] to represent the mechanical behavior as a material involving the damage.

In this study, the tension softening behavior of ASR damaged concrete is experimentally evaluated. Three-point bending test for single notched concrete beams was carried out to determine the fracture properties, such as a 
Table 1: Mix proportion of the concrete

\begin{tabular}{|c|c|c|c|c|c|c|c|c|c|c|c|c|}
\hline \multirow{2}{*}{$\begin{array}{l}\mathrm{G}_{\max } \\
\mathrm{mm}\end{array}$} & \multirow[b]{2}{*}{$\begin{array}{l}\text { Slump } \\
\mathrm{cm}\end{array}$} & \multirow[b]{2}{*}{$\begin{array}{l}\mathrm{W} / \mathrm{C} \\
\%\end{array}$} & \multirow[b]{2}{*}{$\begin{array}{l}\text { Air } \\
\%\end{array}$} & \multirow[b]{2}{*}{$\begin{array}{l}\mathrm{s} / \mathrm{a} \\
\%\end{array}$} & \multicolumn{8}{|c|}{$\mathrm{kg} / \mathrm{m}^{3}$} \\
\hline & & & & & $\mathrm{W}$ & $\mathrm{C}$ & $\mathrm{S}_{\mathrm{n}}$ & $\mathrm{S}_{\mathrm{r}}$ & $\mathrm{G}_{\mathrm{n}}$ & $\mathrm{G}_{\mathrm{r}}$ & $\mathrm{NaCl}$ & $\begin{array}{l}\mathrm{AE} \text { water } \\
\text { redu. agent }\end{array}$ \\
\hline 20 & 18 & 63 & 5 & 48 & 181 & 287 & 422 & 432 & 466 & 475 & 12.4 & $575 \mathrm{ml}$ \\
\hline
\end{tabular}

$\mathrm{S}_{\mathrm{n}}$ : no-reactive fine aggregate, $\mathrm{S}_{\mathrm{r}}$ : reactive fine aggregate,

$\mathrm{G}_{\mathrm{n}}$ : no-reactive aggregate, $\mathrm{G}_{\mathrm{r}}$ : reactive aggregate

tension softening curve and fracture energy. These fracture properties are determined from the propagation of mode I crack in the bending test on the concrete beams. This is based on an assumption that the microscopic damage in the concrete is located in the interface of the matrix to both fine and coarse aggregates and uniformly distributed through the beam.

The previous study presented by the authors $[2,3]$ has showed that he strain distribution obtained by the image analysis can be measured the cracking behavior on the concrete surface under the external load. To detect these crack propagation behavior, an image analysis was carried out during the loading test in order to measure the strain distribution on the concrete beam. As for the macro damage in the concrete the ASR induced cracks that can be observed on the concrete surface are evaluated and classified into their widths, lengths and directions.

\section{EXPERIMENT OUTLINES}

\subsection{Specimens}

The concrete specimen is a beam in which the section is $100 \mathrm{~mm}$ of width, $50 \mathrm{~mm}$ of a ligament height and $800 \mathrm{~mm}$ of the clear span length. The specimen has a single notch at the midspan whose depth was set as $50 \mathrm{~mm}$. Four specimens from ASR-1 to ASR-4 which were exposed outside for about 3 years and two specimens ASR-5 and ASR-6 which were exposed for about 4 years were prepared in this experiment. It is confirmed that an expansion which has been measured by using reference prism specimens of $100 * 100 * 200$ $\mathrm{mm}$ was around $1200 \mu$ or more at the day of bending test for the series of ASR-1 to ASR-4.

The mix proportion of this concrete is

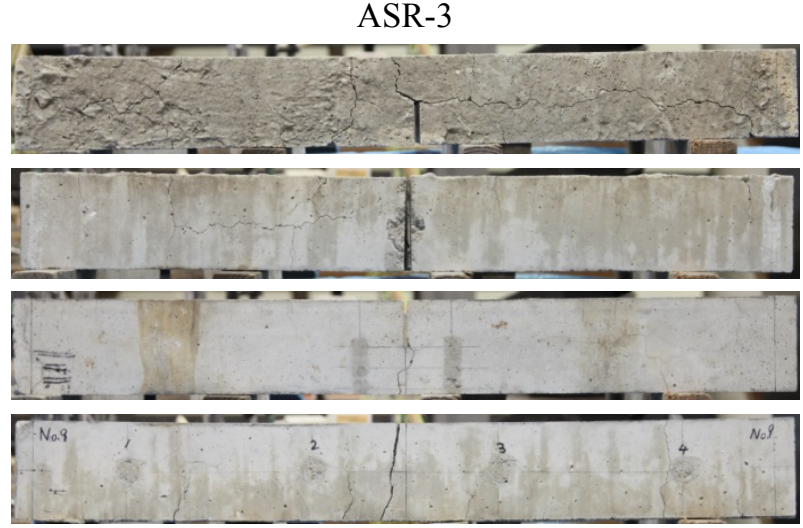

ASR-4
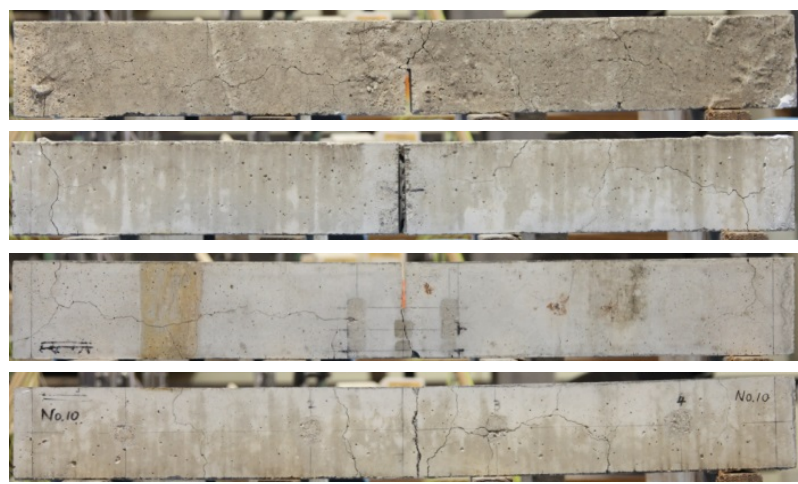

Photo 1. Photo of ASR cracks on the specimens ASR-3 and ASR-4 after bending test

showed in Table 1. Ordinary portland cement for cement and $\mathrm{AE}$ water reducing agent for admixture were used. The maximum size of cause aggregate is $20 \mathrm{~mm}$. Both fine and coarse aggregates were mixed where the ratio of reactive and nonresponsive aggregates in the volume of 1:1 that was decided as a pessimum content. Each specimen was made by the same concrete mix.

The situation of ASR induced cracks, however, was different because of variability of the material and exposure condisions as shown in Photo 1. This is an example of the damage conditions in the specimens tested.

In this study, the compressive strength 


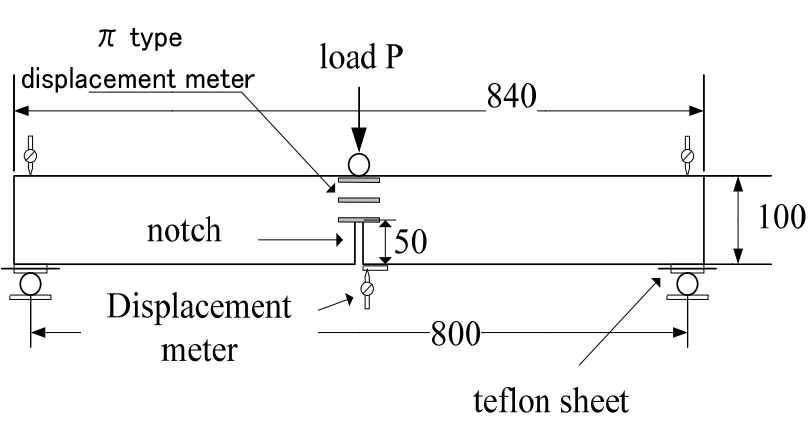

Figure 1: Outlines of the loading test

measured with using cylinder specimens having a diameter of $100 \mathrm{~mm}$ and a height of $200 \mathrm{~mm}$, which is same specified concrete mix as beam specimens, was $31.6 \mathrm{~N} / \mathrm{mm}^{2}$ and the tensile strength was $2.90 \mathrm{~N} / \mathrm{mm}^{2}$.

\subsection{Three-point bending test}

The loading setup in the experiment is illustrated in Figure 1. During the loading test, the load, displacements at both supports and midspan, crack opening displacements, and digital images for an image analysis were measured. For the purpose of the friction reduction at each support, a set of Teflon sheets lubricated with grease was used. The crack opening displacement in the ligament was measured using $\pi$-shape displacement transducers.

\subsection{Image analysis}

In this study, to detect these crack propagation behaviour, an image analysis by using a digital image correlation method was carried out during the loading test in order to measure the strain distribution on the concrete beam. In this method of image analysis, region-based matching technique is used to calculate the displacement of any portion of the concrete surface. The correlated region of dozens of pixel (50 to 100 pixels were set) in the digital pictures which is obtained before/after the deformation under loading is search based on the distribution of the luminance values. In addition, the accuracy of location of the searched region is assumed based on the sub-pixel error cancellation [4].

From distance between a coordinate in the digital image before the loading and that in an arbitrary loading, the displacement of a target point is calculated. Using the isoparamtric finite element that has nodal points of the target point, the strain distribution in the finite element is interpolated according to the deformation under the loading. In this study, maximum principal strain at each load level is observed to evaluate crack propagation behavior.

\section{RESULTS AND DISCUSSION}

\subsection{Fracture energy}

Load-midspan deflection relationships obtained from the three-point bending tests for the specimens of $\mathrm{N}$ series and ASR series are shown in Figures 2 and 3, respectively. The fracture energies obtained from these results were summarized in Figures 4. Here, the $G_{F}$ is determined from Equation (1).

Figure 3. Load-midspan deflection relathinships (ASR series)

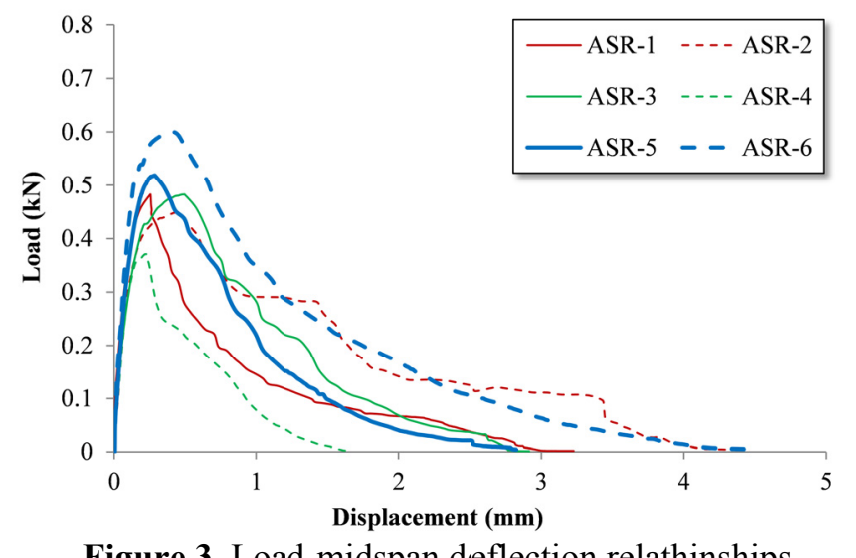

Figure 2. Load-midspan deflection relathinships

rection relathinships
(N series)
Figure 2. Load-midsp
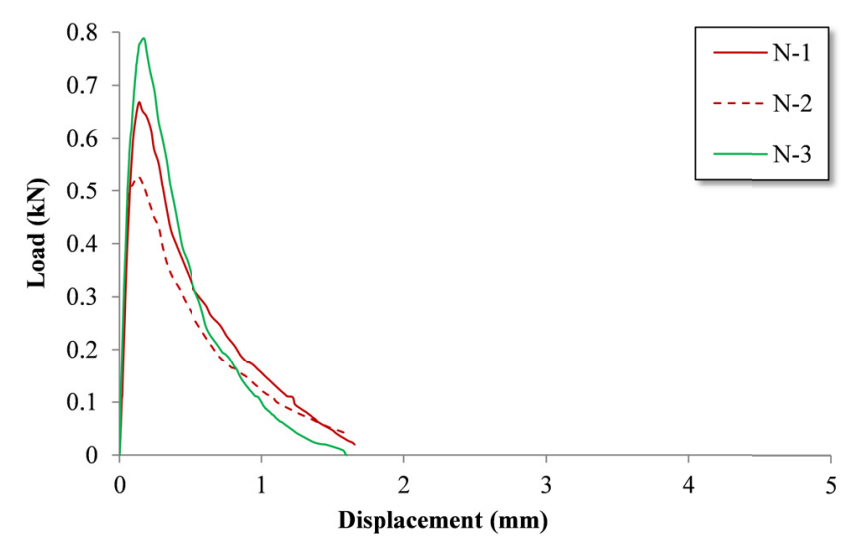


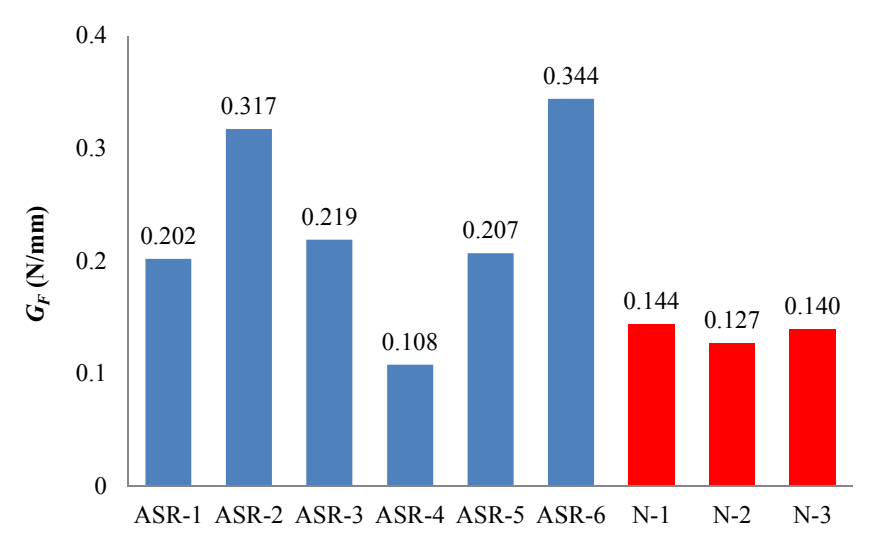

Figure 4. Fracture energy

$$
G_{F}=\left(W_{0}+m g \cdot \delta_{\text {max }}\right) / A_{\text {lig }}
$$

where, $W_{0}$ : the area under the loaddisplacement curve $(\mathrm{N} \cdot \mathrm{mm}), m g$ : the specimen weight $(\mathrm{N}), \delta_{\max }$ : the maximum displacement $(\mathrm{mm}), A_{\text {lig: }}$ the cross-sectional area of the ligament $\left(\mathrm{mm}^{2}\right)$

The averaged maximum load for the sound specimen ( $\mathrm{N}$ series) was $0.66 \mathrm{kN}$ and that among the ASR damaged specimens (ASR series) was $0.48 \mathrm{kN}$, respectively. The displacement at the ruptured was $1.61 \mathrm{~mm}$ for the $\mathrm{N}$ series and $2.97 \mathrm{~mm}$ for the ASR series, respectively.

As seen in Figure 4, the fracture energy for the specimens of ASR series is larger than that of $\mathrm{N}$ series. This can be understood from Figures 2 and 3, since the fracture energy is calculated by the Equation (1) and the area under the load-displacement curve, $W_{0}$. Especially, the bending load remains after peak and decrease gradually until the notched beam specimen has been raptured under the bending. This means that the crack propagation under an external load may delay due to the presence of existing ASR induced cracks which occur at the aggregate surface, and consequently the crack propagated sluggishly.

The averaged value of fracture energy was $0.212 \mathrm{~N} / \mathrm{mm}$ for the specimens ASR-1 to ASR-4, while $0.276 \mathrm{~N} / \mathrm{mm}$ for the ASR-5 and ASR-6. It is interesting that the fracture energy increased as the damage level increases. This tendency may be explained by the condition of the cracks occurring within the ligament portion. To clarify the reason of this behavior, the image analysis for this domain was carried out and the results are discussed in the following section.

\subsection{Tension softening curve}

The tension softening curves obtained from the three-point bending tests are summarized in this section. Figures 5 and 6 show the tension softening curves for the sound specimens ( $\mathrm{N}$ series) and the ASR damaged specimens (ASR series), respectively. In this study, the fracture properties are assumed to be determined from the propagation of mode I crack in the bending test on notched concrete beams. It should be noted that this is based on an assumption that the microscopic ASR damage in the concrete is distributed uniformly through the concrete beam.

In the previous study [2], it has been confirmed that the crack occurred under

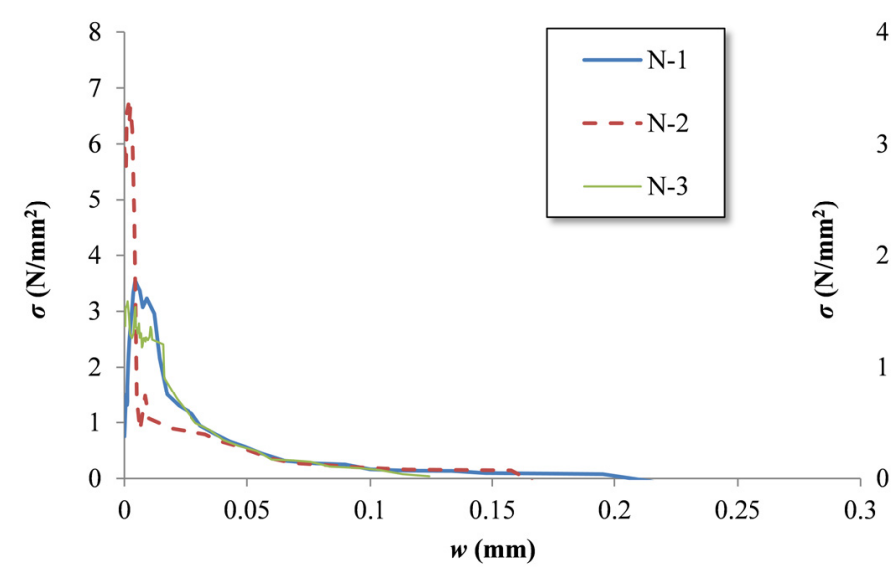

Figure 5. Tension softening curves (N series)

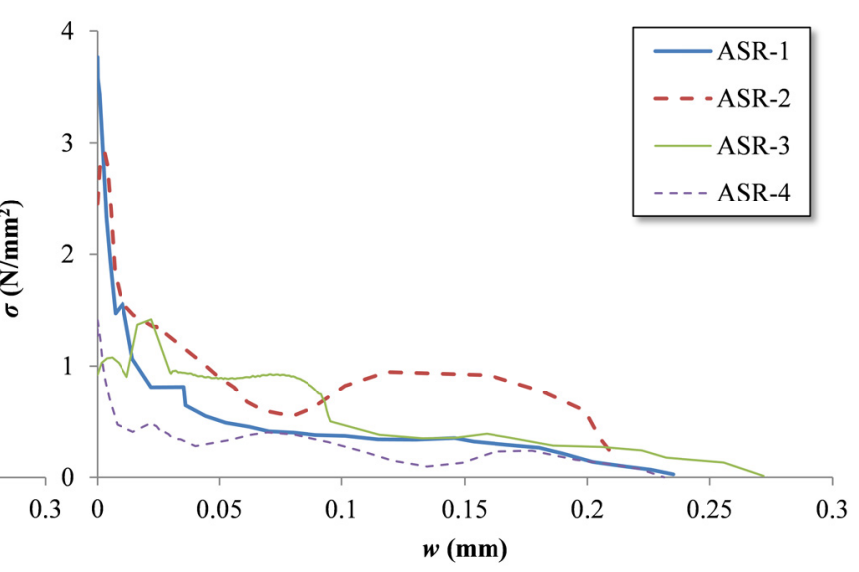

Figure 6. Tension softening curves (ASR series) 

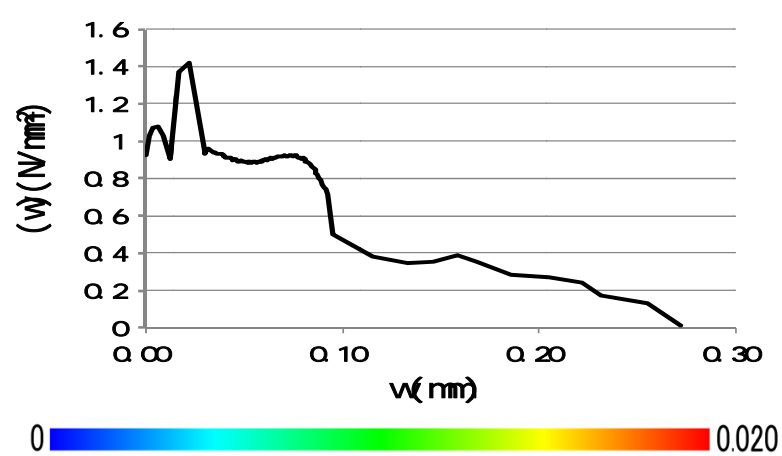

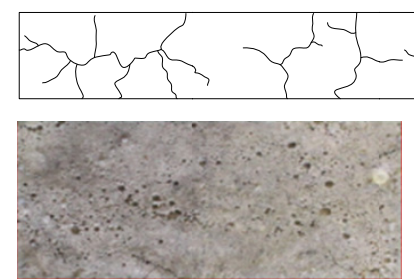

(a) Target domain

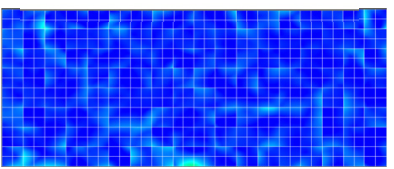

(c) $\mathrm{w}=0.0946 \mathrm{~mm}$

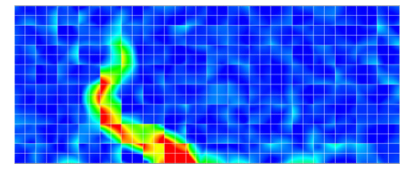

(e) $\mathrm{W}=0.206 \mathrm{~mm}$

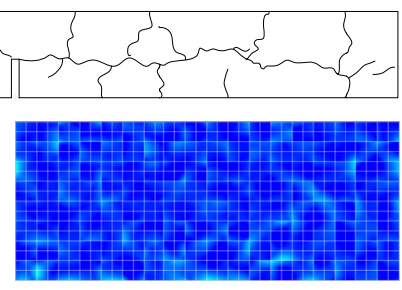

(b) $\mathrm{w}=0.0164 \mathrm{~mm}$

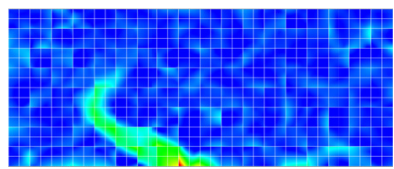

(d) $\mathrm{w}=0.115 \mathrm{~mm}$

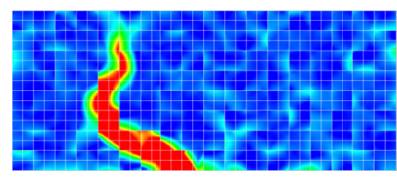

(f) $\mathrm{w}=0.297 \mathrm{~mm}$
Figure 7. Tension softeing curve and distrribution of maximum principle strain at the ligament of specimen ASR-3

external loading has propagated along ASRinduced crack existing around the notch tip in the ligament of the notched beam. In addition, the ASR-induced crack that has existed horizontally at the notch tip opened with the increase in the external force.

Comparing the tension softening curves among the ASR series, we can confirm that the initial stress differs each other around 1.0-2.5 $\mathrm{N} / \mathrm{mm}^{2}$. The initial stresses of the ASR series are smaller as compared to that of the specimens of $\mathrm{N}$ series. As for the specimens of ASR series, the stress at the bridging zone that is within the fictitious crack opening displacement (COD) of 0.02-0.05 $\mathrm{mm}$ remains and decreases gradually until the COD reaches $0.25 \mathrm{~mm}$.
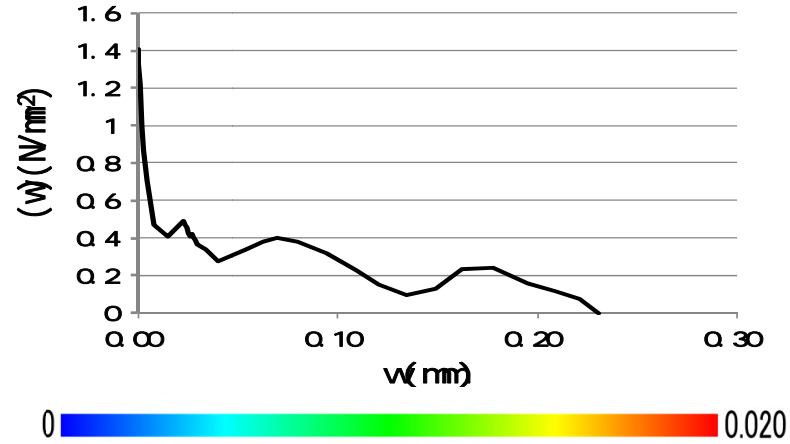

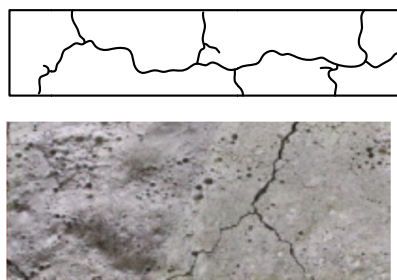

(a) Target domain

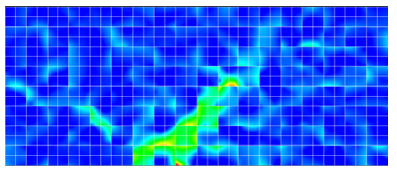

(c) $\mathrm{w}=0.0947 \mathrm{~mm}$

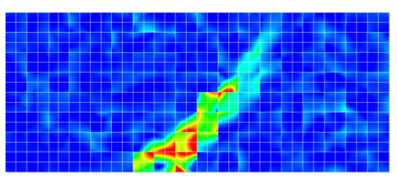

(e) $\mathrm{w}=0.163 \mathrm{~mm}$

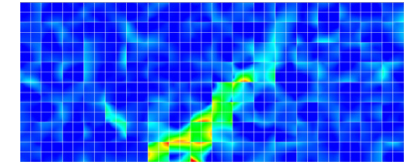

(d) $\mathrm{w}=0.121 \mathrm{~mm}$

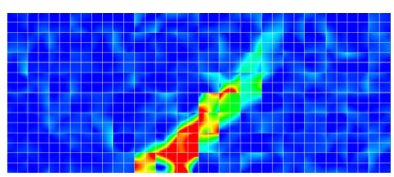

(f) $\mathrm{w}=0.229 \mathrm{~mm}$
Figure 8. Tension softeing, curve and distrribution of maximum principle strain at the ligament of specimen ASR-4

\subsection{Maximum principal-strain distribution}

Figures 7 and 8 show the distribution of the maximum principal strain in the specimens ASR-3 and ASR-4 respectively as an example result of the image analysis. The result of the image analysis was conducted at the midspan deflection corresponding to the fictitious crack width, $w(\mathrm{~mm})$ as shown in this figure. In addition, the picture of the ligament portion in the figure is of that before loading and a domain as the image analysis target $(100 \mathrm{~mm}$ in width, $50 \mathrm{~mm}$ in height). The subset size corresponding to one finite element that was used to calculate the strain was set as $50 * 50$ pixels in this image analysis.

In these figures, the close-up photo at the ligament of the specimen indicates that there is no macroscopic crack before the loading for 

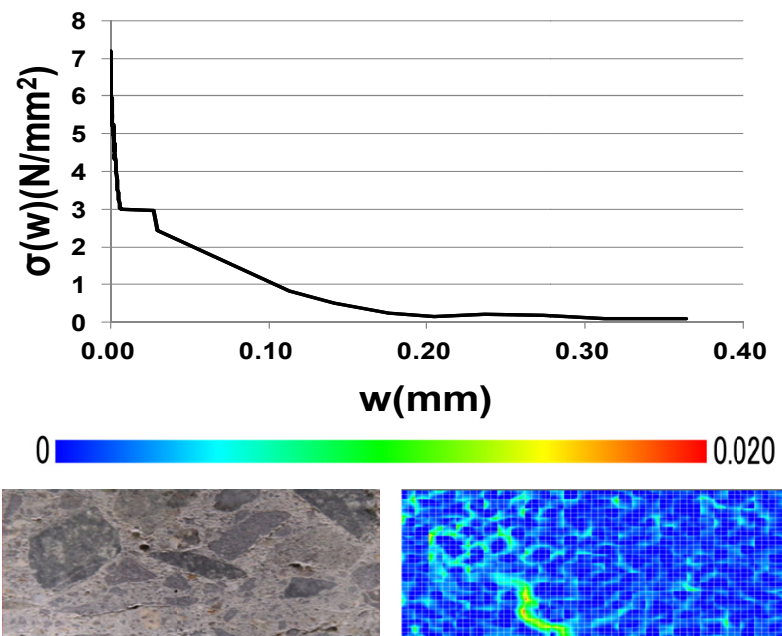

(a) Target domain

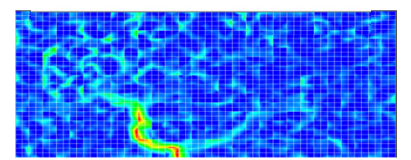

(c) $\mathrm{w}=0.0273 \mathrm{~mm}$

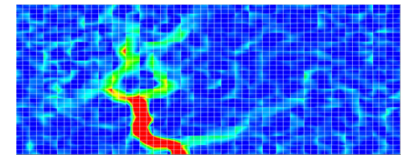

(e) $\mathrm{w}=0.113 \mathrm{~mm}$

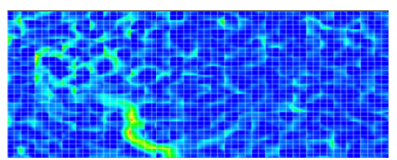

(b) $\mathrm{w}=0.00501 \mathrm{~mm}$

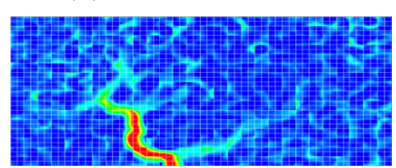

(d) $\mathrm{w}=0.0512 \mathrm{~mm}$

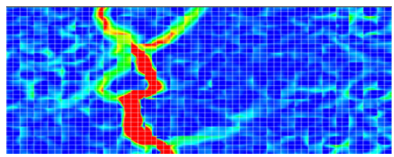

(f) $\mathrm{w}=0.205 \mathrm{~mm}$

Figure 9. Tension softening curve and distribution of maximum principle strain at the ligament of specimen ASR-3-1-2 (after polished)

the specimen ASR-3, while the ASR-induced cracks can be seen in the specimen ASR-4. In the previous study [2], it has been confirmed that the ASR-induced crack that has existed horizontally at the notch tip opened with an increase in the external load. The tension softening curve for the specimen ASR-3 illustrated in Figure 7 indicates that the tensile stress rapidly decreases from $0.9 \mathrm{~N} / \mathrm{mm}^{2}$ to 0.4 $\mathrm{N} / \mathrm{mm}^{2}$ at the fictitious COD of $w=0.10 \mathrm{~mm}$. As for the maximum principle strains between at $w=0.0946 \mathrm{~mm}$ and at $w=0.115 \mathrm{~mm}$ the tensile strain increases within this stage and consequently the crack propagates upward directing to the loading point.

In contrast, the specimen ASR-4 indicates that the tensile stress decreases just after an initiation of the crack opening, as seen in Figure 8. The tensile principle strain has started to localize at a tip of the notch at the fictitious COD of $w=0.0341 \mathrm{~mm}$. This is because of the presence of the existing ASR-

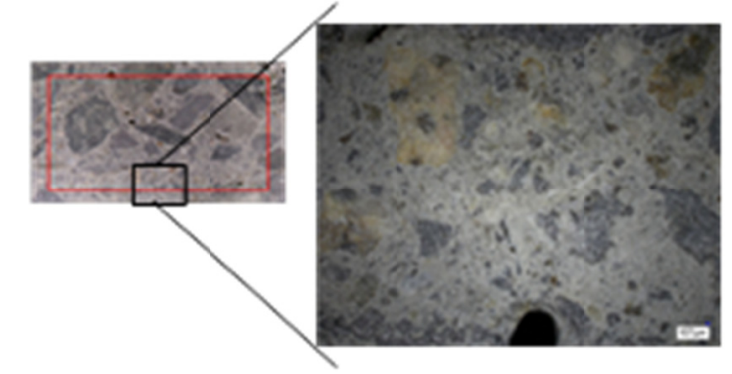

0 0.020

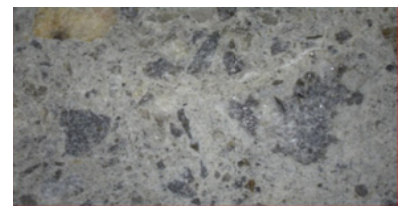

(a) Target domain

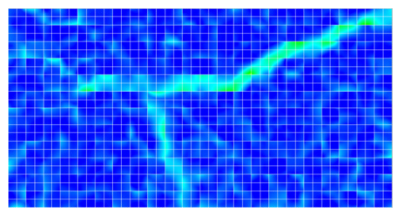

(c) $\mathrm{w}=0.00346 \mathrm{~mm}$

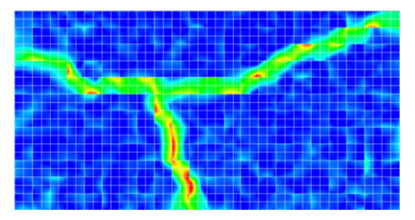

(e) $\mathrm{W}=0.00715 \mathrm{~mm}$

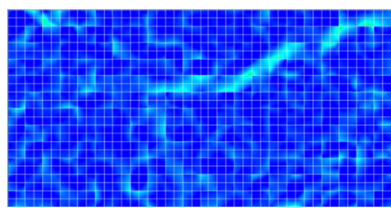

(b) $\mathrm{w}=0.00208 \mathrm{~mm}$

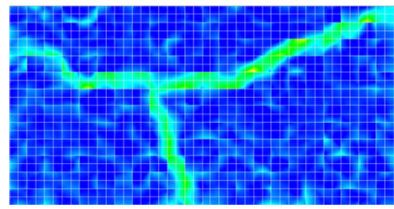

(d) $\mathrm{W}=0.00510 \mathrm{~mm}$

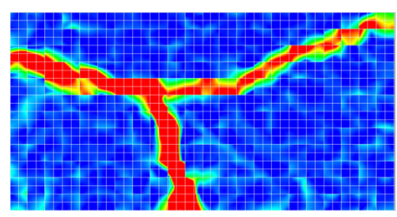

(f) $\mathrm{w}=0.0131 \mathrm{~mm}$
Figure 10. Micro scope view for the distribution of maximum principle strain at the ligament of specimen ASR-3-1-2 (after polished)

induced crack within a domain at the notch tip in the ligament of the beam.

Figure 9 shows the tension softening curve and distribution of maximum principle strain at the ligament of specimen ASR-3-1-2. This specimen of ASR-3-1-2 was prepared using the specimen ASR-3 where the raptured prism after terminating the loading test were curved within the thickness of around $10 \mathrm{~mm}$ and polished the surface of concrete. Hence the aggregate in the concrete can be confirmed from the surface of specimen as shown in Figure 9. The distribution of maximum principle strain at the ligament of specimen indicates that the crack propagates in a path along with the interfacial zone between course aggregate and matrix.

In order to confirm an effect of the existing crack on the crack propagation under external 
load the close-up view on this domain was further investigated. A digital microscope was used to capture this behavior of the micro cracks. The crack propagation until peak load in the bending test is shown in Figure 10. In the very initial stage of the fictitious COD of $\mathrm{w}=0.00208 \mathrm{~mm}$, a micro crack that occurs in the horizontal direction can be confirmed by using the obtained image analysis. It can be also confirmed that this micro crack at the tip pf the notch clearly affects the crack propagation under external load. This result reveals that, the quantitative evaluation on the state of the ASR-induced crack at the ligament portion is needed in order to evaluate the influence of the ASR-induced crack on the fracture properties of the concrete.

\section{CONCLUSIONS}

The effect of the ASR-induced cracks on the tension softening behavior of the concrete was experimentally evaluated in this study. The three-point bending test for single notched concrete beams was carried out and the fracture energy and tension softening curves of the ASR damaged concrete were obtained. To detect the crack propagation behavior, the image analysis by using a digital image correlation method was carried out during the loading. We conclude that the experiments show that the ASR induced cracks visible on the concrete surface do not always influence the crack propagation occurred under the external loading. From these results, in order to evaluate the influence of the ASR-induced crack on the fracture properties of the concrete, the quantitative evaluation on the state of the ASR-induced crack at the ligament portion is needed.

\section{Acknowledgements:}

This research was partially supported from the Japan Society for the Promotion of Science (JSPS), Grant-in-Aid for Scientific Research (A) (JSPE KAKENHI Grant \#22246061).

\section{REFERENCES}

[1] Saouma, V. and Perotti, L., 2006. Constitutive Model for Alkali-Aggregate Reactions, ACI Mat. J., 103(3), 194-202

[2] Miki, T., Matsutani, K. and Miyagawa, Y., 2013. Evaluation of Crack Propagation in ASR Damaged Concrete Based on Image Analysis, FraMCoS, 8, 1787-1794

[3] Miki, T., Matsutani, K. and Tsukahara, H., 2015. Tension Softening Behavior of ASR Damaged Concrete Detected by Image Analysis, Proc. of 5th Int. Conf. on Const. Mat., 5, 2260-2269, 2015

[4] Shimizu, M. and Okutomi, M., 2005. Subpixel Estimation Error Cancellation on Area-based Matching. Int. J. of Comp. Vision, 63(3), 207-224. 